\title{
Dual-Polarization Radar Analysis of Northwestern Nevada Flash Flooding and Haboob: 10 June 2013
}

\author{
DAVID T. MYRICK \\ NOAA/National Weather Service, Reno, Nevada \\ JEREMY R. MICHAEL \\ NOAA/National Weather Service, Elko, Nevada
}

(Manuscript received 29 October 2013; review completed 8 January 2014)

\begin{abstract}
A slow-moving complex of thunderstorms formed across northwestern Nevada on 10 June 2013 in the deformation zone of an approaching upper-level low-pressure system. Storm redevelopment along outflow boundaries resulted in urban and rural flash flooding. On the eastern flank of the thunderstorm complex, strong outflow boundaries lofted dust to form a large haboob. The haboob propagated eastward across northcentral Nevada and resulted in a 27 -car pileup on Interstate 80 near Winnemucca. Three examples are presented that demonstrate how dual-polarization radar technology aided forecasters in (i) discriminating heavy rain from hail and (ii) tracking the haboob.
\end{abstract}

\section{Introduction}

A slow-moving complex of thunderstorms developed in a deformation zone across northwestern Nevada on 10 June 2013 that resulted in flash flooding and a large haboob. The thunderstorms formed in an unstable, low-shear environment ahead of an approaching upper-level trough with rapid storm redevelopment along outflow boundaries. Flash flooding and accumulating hail impacted the community of Spanish Springs (Fig. 1a) and washed out sections of rural state highway 447 to the east of Pyramid Lake (Fig. 1b). As the flooding unfolded, strong outflow boundaries emanating from the complex of thunderstorms surged eastward into a much drier environment across northcentral Nevada. The strong winds lofted dust and produced a large haboob (Fig. 1c), which is a dust storm generated by thunderstorm outflows (Idso et al. 1972). Reduced visibility from the haboob led to a $27-$ car pileup on Interstate 80 near Winnemucca, Nevada.

Flash floods are most commonly observed during the summer months across northwestern Nevada from convective rainfall events (Brong 2005). Warning operations for flash flooding is particularly challenging, owing to the complex topography of the region
(Fig. 2), the arid climate, and radar sampling issues ${ }^{\mathbf{1}}$. To aid in operational flash-flood forecasting, Brong (2005) examined 22 flash-flood events between 1994 and 2003 across western Nevada and classified them into three synoptic patterns. Two of the patterns are related to the location of surface high pressure and how it can limit storm motions (Great Basin High) and introduce subtropical moisture into western Nevada (Four Corners High). The third and most frequently observed pattern (Upper Low) occurs when an upperlevel trough approaches from the west. As will be shown in section 2, the 10 June 2013 event fits into the Brong (2005) Upper-Low pattern.

The arid climate and geography of northwestern Nevada makes it susceptible to blowing dust events. The primary source regions for lofted dust are dry lake beds and alkali deserts located within the Pleistocene Lake Lahontan to the north and east of Reno. The most prominent geographic sources are the Black Rock Desert and the Carson and Humboldt Sinks (see Fig. 2 for locations). Steenburgh et al. (2012) found that loft-

\footnotetext{
1 The KRGX (KLRX) WSR-88D radar antenna is located at an elevation of $2558 \mathrm{~m}(2101 \mathrm{~m})$, approximately $1200 \mathrm{~m}(550 \mathrm{~m})$ above the main population center near Reno, NV (Elko, NV).
} 


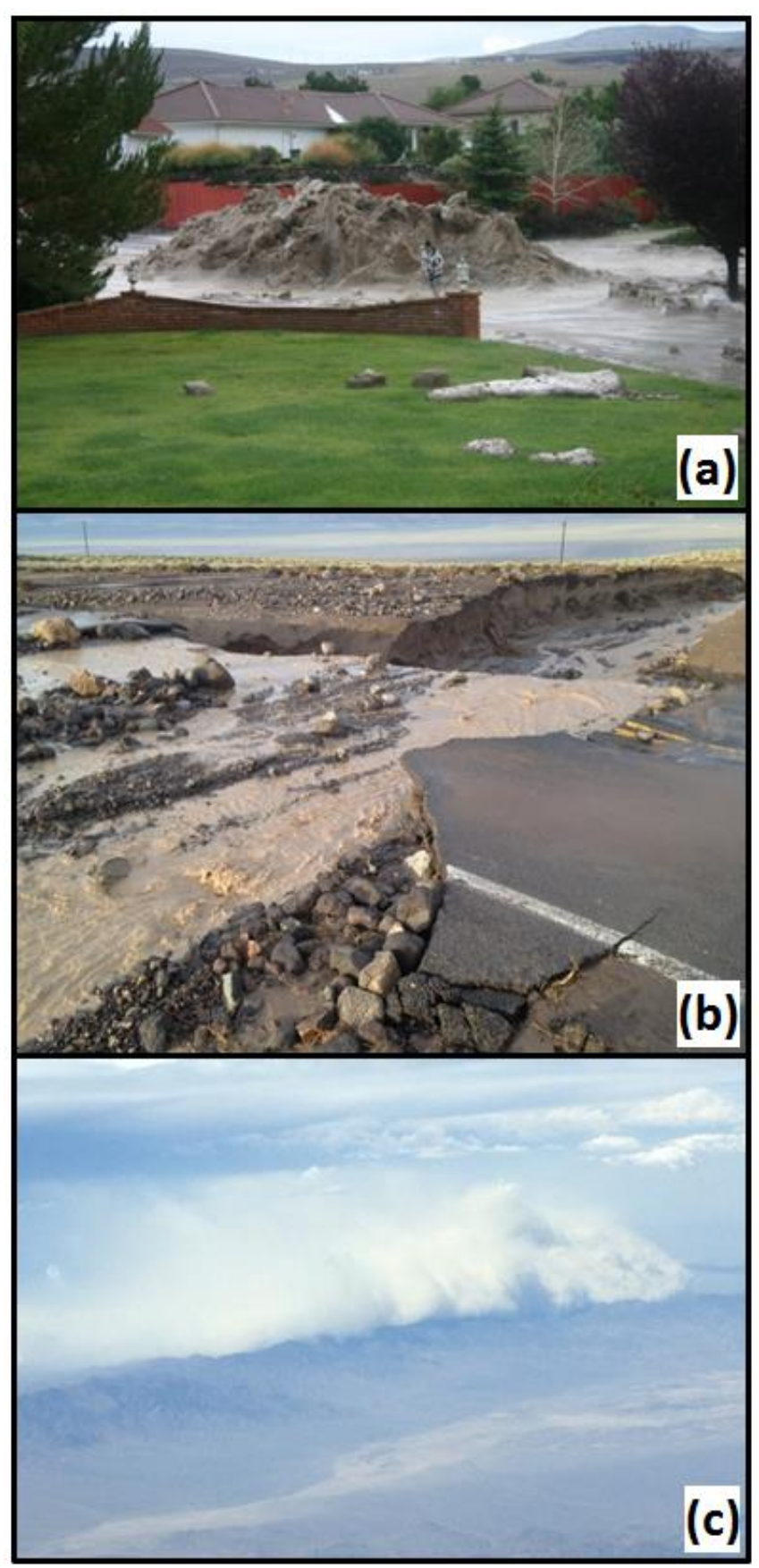

Figure 1. Event photographs of: (a) pile of hail created by snow plows in Spanish Springs, NV (photograph by S. Smith); (b) road damage on state highway 447 (photograph courtesy of the NV Department of Transportation); and (c) aerial photo of the haboob when it was located approximately $50 \mathrm{~km}$ south of Winnemucca, NV (photograph by C. Eyring). Click image for an external version; this applies to all figures hereafter.

ed dust from these sources can be observed as far away as Elko, Nevada, and Salt Lake City, Utah. Climatologies by Orgill and Sehmel (1967) and Changery (1983) based on National Weather Service

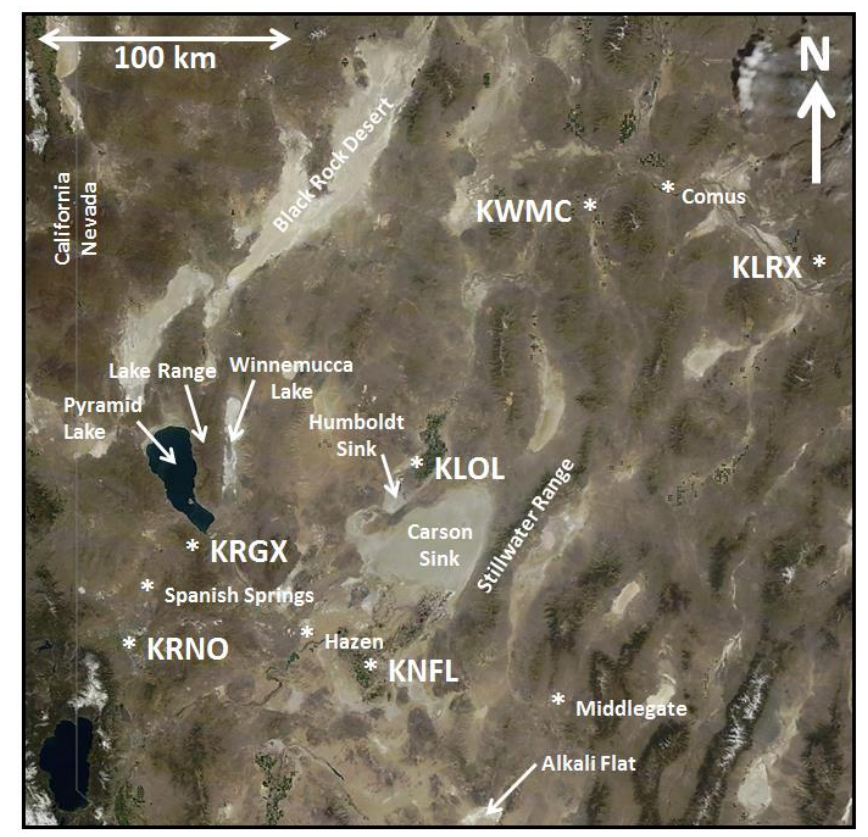

Figure 2. Moderate Resolution Imaging Spectroradiometer (MODIS) image over northwestern NV on a clear day, annotated with key geographic locations. Abbreviations include KNFL (Fallon), KLOL (Lovelock), KLRX (Elko WSR-88D), KRGX (Reno WSR-88D), KRNO (Reno), and KWMC (Winnemucca). Image courtesy of the Space Science and Engineering Center at the University of Wisconsin-Madison [ge.ssec.wisc.edu/modis-today/ index.php].

(NWS) and military surface observations found a local maximum in blowing dust events across northwestern Nevada near Lovelock (KLOL), where visibility reductions to $<1 \mathrm{~km}$ were observed an average of 12.3 h $\mathrm{yr}^{-1}$ between 1948 and 1977 (Changery 1983). Dust storms can occur year round across northern Nevada; however, the mechanism driving these events can vary by time of year. Recent work by Kaplan et al. (2011) and Lewis et al. (2011) examined cool-season dust storms across northwestern Nevada driven by synoptic-scale processes. This case study examines a warmseason event where the blowing dust was forced by a strong thunderstorm outflow boundary.

Dual-polarization technology was added to NWS Weather Surveillance Radar-1988 Doppler (WSR88D) radars in 2012-13 (Istok et al. 2009; Saxion and Ice 2012). Prior to the upgrade, WSR-88D radars transmitted pulses of electromagnetic radiation in a single (horizontal) plane. By transmitting pulses of electromagnetic radiation simultaneously in two different planes (horizontal and vertical), dual-polarization provides NWS operational forecasters new variables and algorithms that can be used to assess the size, shape, and orientation of radar targets (Kumjian 
2013a,b). For a complete history of dual-polarization radar, a description of the new variables, and a discussion of data quality issues, please see the review papers by Kumjian (2013a,b,c).

This case study examines how the new WSR-88D dual-polarization radar products can be used to assess flash flooding, hail, and blowing dust in a data-sparse region with poor low-level radar coverage. Section 2 describes the antecedent conditions across northwestern Nevada prior to thunderstorm initiation on 10 June 2013. Three examples are presented in section 3 that demonstrate how the new products assisted NWS forecasters in discriminating hydrometeor type during the event. A summary and brief discussion of limitations of high-elevation radars are provided in section 4.

\section{Pre-storm environment}

An upper-level low-pressure system lifted northeast across central California and central Nevada on 10 June 2013. To analyze the synoptic environment, a 4panel 9-h forecast from the 1200 UTC 10 June 2013 North American Mesoscale (NAM) model valid near the peak of thunderstorm activity (2100 UTC 10 June 2013) is shown in Figure 3. The complex of thunderstorms developed within a north-south oriented deformation zone across northwestern Nevada - in a region of relatively light winds at $300-, 500-$ and $700-\mathrm{hPa}$ (denoted by the red ellipses in Figs. 3a, b, and d).

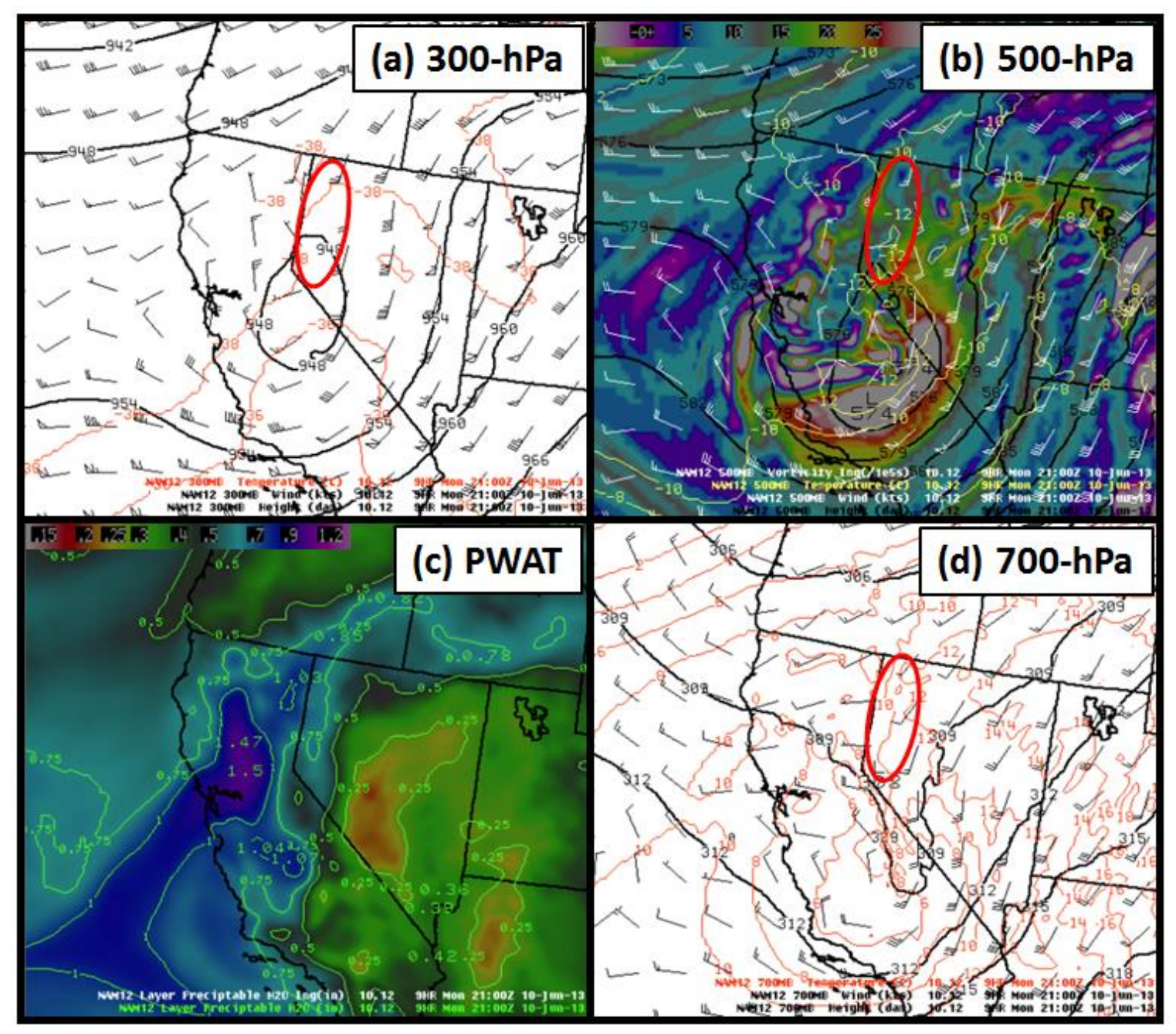

Figure 3. 1200 UTC 10 June 2013 NAM 9-h forecast valid at 2100 UTC 10 June 2013: (a) 300-hPa height (dam; black contours), temperature $\left({ }^{\circ} \mathrm{C}\right.$; red contours), and wind (kt; barbs); (b) 500-hPa height (dam; black contours), temperature $\left({ }^{\circ} \mathrm{C}\right.$; yellow contours), wind (kt; barbs), and absolute vorticity $\left(10^{-5} \mathrm{~s}^{-1}\right.$; shaded); (c) layer precipitable water (in; shaded); and (d) 700-hPa height (dam; black contours), temperature $\left({ }^{\circ} \mathrm{C}\right.$; red contours), and wind (kt; barbs). The red ellipses denote a deformation zone. 
Sufficient deep moisture to support convection was present across northwestern Nevada with forecast precipitable water values near $19.6 \mathrm{~mm}$ (0.75 in) (Fig. $3 c)$. Such values are consistent with the observed value of $19.1 \mathrm{~mm}(0.77 \mathrm{in})$ from the 1200 UTC 10 June 2013 Reno sounding (Fig. 4). Climatologically, precipitable water values $>19.6 \mathrm{~mm}$ (0.75 in) at Reno are in the top quartile for the month of June (Bunkers 2013). These values also meet the criteria for the Brong (2005) Upper-Low flash-flood pattern for western Nevada, which requires a minimum precipitable water value of $15.2 \mathrm{~mm}$ (0.60 in). Farther to the east, a sharp moisture boundary was located across west-central Nevada, with NAM forecast precipitable water values lowering to near $6.4 \mathrm{~mm}$ (0.25 in) across central Nevada (Fig. $3 c)$. It was within this sharp moisture boundary that strong thunderstorm outflows congealed to form the haboob that traversed north-central Nevada.

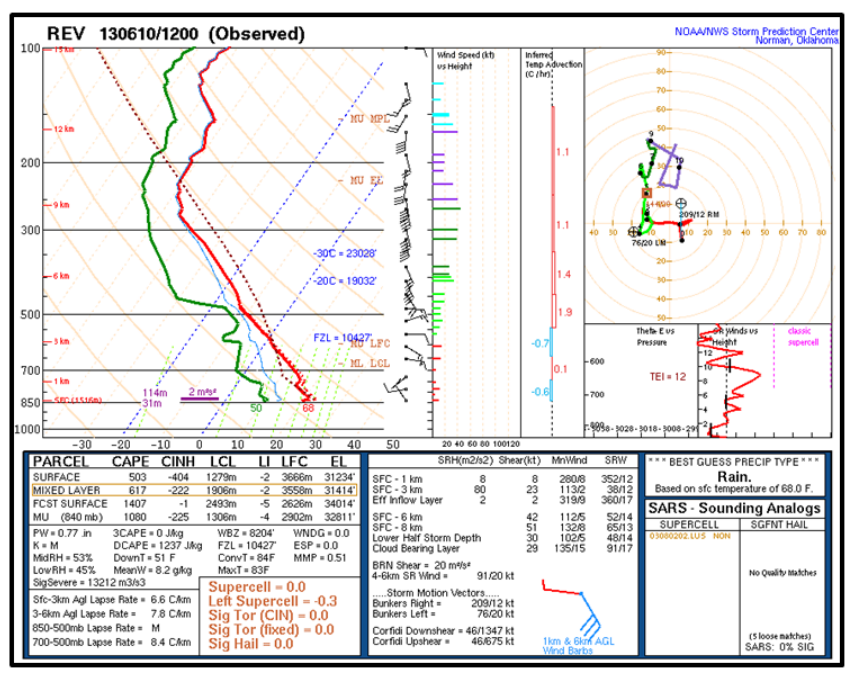

Figure 4. Reno, NV (KREV), sounding valid at 1200 UTC 10 June 2013. Image courtesy of the NOAA/NWS Storm Prediction Center.

Similar to the NAM forecast, the 1200 UTC 10 June 2013 Reno sounding contained relatively light winds below $500 \mathrm{hPa}$ (cf. Figs. 3d and 4). Stronger winds up to $21 \mathrm{~m} \mathrm{~s}^{-1}$ (40 kt) were observed between 500 and $300 \mathrm{hPa}$ (Fig. 4). The winds above $500 \mathrm{hPa}$ decreased as the deformation band developed across northwestern Nevada in the early afternoon. At the peak of the observed convection (approximately 2200 UTC), the NWS Storm Prediction Center (SPC) mesoscale analysis depicted a local minimum in effective bulk shear within the deformation zone across northwestern Nevada (Fig. 5a), indicative of an environment that is not favorable for organized convection.

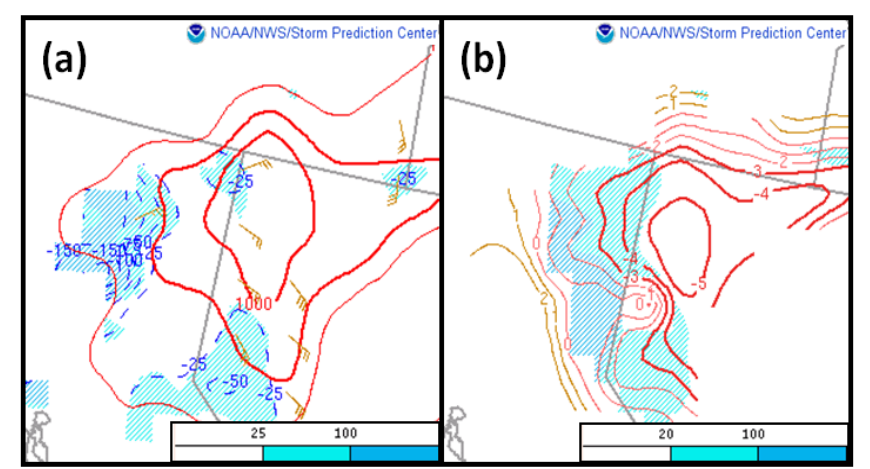

Figure 5. Mesoscale analyses valid at 2200 UTC 10 June 2013 centered over northwestern NV for: (a) most-unstable convective available potential energy ( $\mathrm{J} \mathrm{kg}^{-1}$; red contours), most unstable convective inhibition ( $\mathrm{J} \mathrm{kg}^{-1}$; shaded and blue contours), and effective bulk shear (kt; wind barbs) and (b) surface-based lifted index $\left({ }^{\circ} \mathrm{C}\right.$; red and brown contours) and surface-based convective inhibition ( $\mathrm{J} \mathrm{kg}^{-1}$; shaded). State boundaries are shown in gray. Images courtesy of the NOAA/NWS Storm Prediction Center.

However, the environment within the deformation zone was unstable as the SPC mesoscale analysis depicted over $1000 \mathrm{~J} \mathrm{~kg}^{-1}$ of most-unstable convective available potential energy (Fig. 5a) and lifted indices of -5 (Fig. 5b). As will be shown in section 3, this low-shear, unstable environment supported thunderstorms that rapidly redeveloped along outflow boundaries.

The threat for blowing dust during this event was heightened owing to a prolonged period (16 months) of severe to extreme drought conditions across northwestern Nevada (not shown). These conditions led to a substantial flow reduction in rivers across the region. For example, the observed flow on the Humboldt River at Comus (upstream of the Humboldt Sink, see Fig. 2 for location) on 10 June 2013 was only $1.19 \mathrm{~m}^{3}$ $\mathrm{s}^{-1}\left(42 \mathrm{ft}^{3} \mathrm{~s}^{-1}\right)$ or $4.6 \%$ of the mean daily flow of 25.97 $\mathrm{m}^{3} \mathrm{~s}^{-1}\left(917 \mathrm{ft}^{3} \mathrm{~s}^{-1}\right)$ observed by the United States Geological Survey on 98 different years between 1894 and 2012 (waterdata.usgs.gov/nv/nwis/current/?type= flow). One can hypothesize that reduced inflows into the Humboldt and Carson Sinks increased the amount of exposed dry soils available for lofting during this event.

\section{Dual-polarization radar analysis}

The first cluster of thunderstorms developed approximately $30 \mathrm{~km}$ east of Reno around 1900 UTC 10 June 2013. Deep instability and the interaction of outflow boundaries with terrain features and other outflow boundaries allowed thunderstorm activity to continue within the deformation zone for $\geq 6 \mathrm{~h}$, even 
though the environment lacked shear to organize severe convection. Given the low-centroid structure of the thunderstorms during this event, NWS warning forecasters found it difficult to discriminate between areas of heavy rainfall from small hail using legacy radar products. The following two subsections contain examples that demonstrate how the new dual-polarization products made it easier for forecasters to assess hydrometeor type. A third example is shown that describes how the new products enhanced forecaster capability to identify and track a large haboob.

\section{a. Spanish Springs flash flooding and accumulating hail}

A band of thunderstorms drifted southwest across Spanish Springs, Nevada, between 2015 and 2115 UTC, and produced roadway flooding and pea-sized hail up to a depth of $63.5 \mathrm{~mm}$ (2.5 in). A six-panel of 0.5-degree and derived data from the Reno WSR-88D (KRGX) centered over Spanish Springs at 2034 UTC is shown in Fig. 6. Using reflectivity and other legacy radar base products (velocity and spectrum width; not shown), NWS forecasters found it difficult to discriminate between areas of heavy rain and small hail within the region of high reflectivity (55-65 dBZ) in Fig. 6a because of the low-centroid structure of the thunderstorms. However, the new dual-polarization base and derived products helped forecasters to better assess hydrometeor type. For example, sharp contrasts along the line of thunderstorms in differential reflectivity $\left(Z_{\mathrm{DR}} ;\right.$ Fig. $\left.6 \mathrm{~b}\right)$ and specific differential phase $\left(K_{\mathrm{DP}}\right.$; Fig. $6 c)$ - combined with uniform high values of correlation coefficient ( $\rho_{\text {hv }}$; Fig. 6d) - increased forecaster confidence that heavy rain was occurring along the western flank near Spanish Springs Airport (denoted by the white ellipses in Fig. 6) with small hail occurring along the eastern flank (denoted by the black boxes in Fig. 6). The NWS WSR-88D hydrometeor classification algorithm (HCA) also supported this analysis (Fig. 6e), further increasing forecaster confidence in precipitation type.

Following the event, a postmortem analysis revealed the value of reviewing vertical cross sections of dual-polarization base products to analyze precipitation type in low-centroid thunderstorms. A vertical cross section of WSR-88D data through the line of storms (along the white line A-B in Fig. 6d) valid at 2034 UTC is shown in Fig. 7. Note that the bottom of the cross sections shown in Fig. 7 are roughly $1372 \mathrm{~m}$ $(4500 \mathrm{ft})$ above ground level (AGL) or $2743 \mathrm{~m}$ (9000

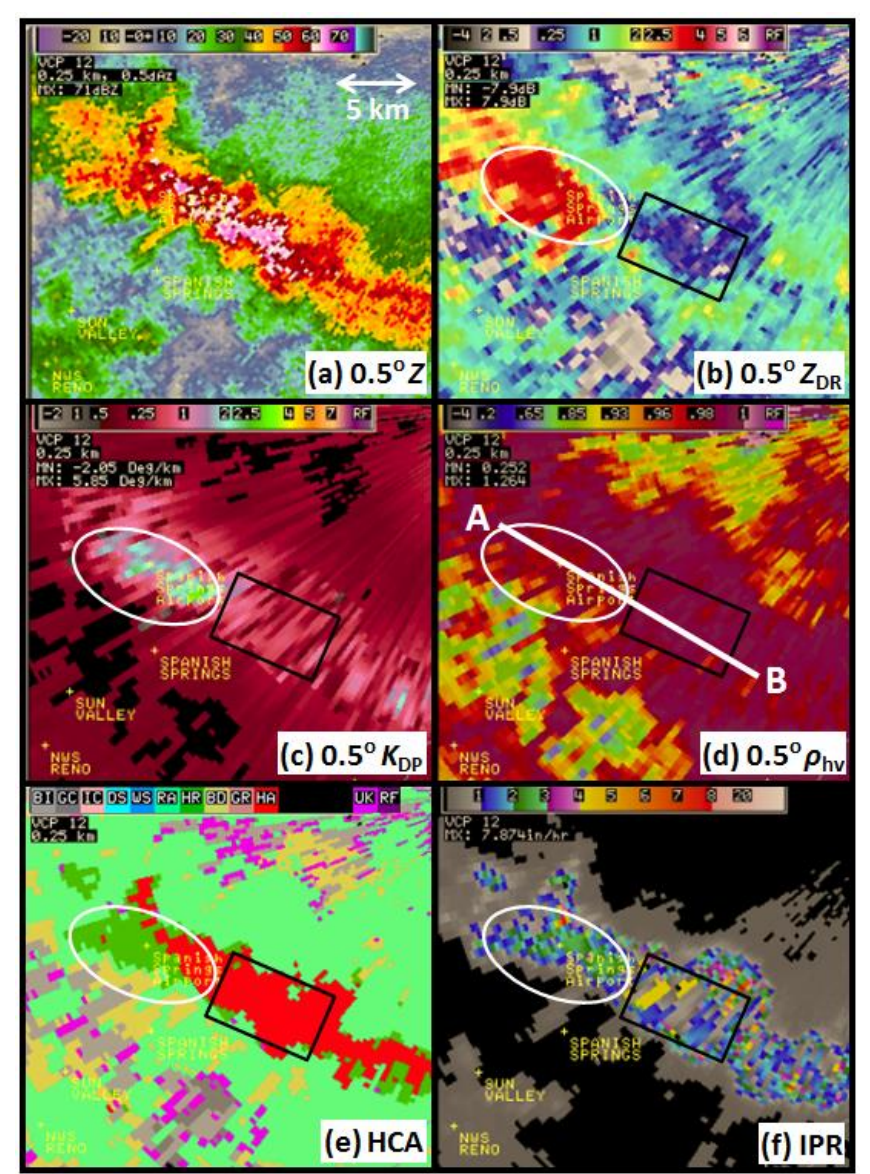

Figure 6. KRGX WSR-88D data valid at 2034 UTC 10 June 2013 near Spanish Springs, NV. (a) 0.5-degree reflectivity (dBZ); (b) 0.5 -degree differential reflectivity $(\mathrm{dB})$; (c) 0.5-degree specific differential phase $\left(\mathrm{deg} \mathrm{km}^{-1}\right)$; (d) 0.5 -degree correlation coefficient; (e) hydrometeor classification algorithm; and (f) instantneous precipitation rate (in $\mathrm{hr}^{-1}$ ). The white ellipses (black boxes) in (b)-(f) denote the location of the western flank (eastern flank) of the line of thunderstorms. The white line A-B in (d) denotes the location of the cross section shown in Fig. 7.

$\mathrm{ft}$ ) above sea level (ASL; the elevation of the lowest radar slice near Spanish Springs). Similar to the 0.5degree data (Fig. 6a), it is difficult to discern precipitation type using reflectivity alone (Fig. 7a). An argument could be made that small hail was present as reflectivity values $>60 \mathrm{dBZ}$ were analyzed above the $-20^{\circ} \mathrm{C}$ level [5800 m (19 $\left.032 \mathrm{ft}\right)$ ASL]. Below the melting level [3178 m (10 $427 \mathrm{ft})$ ASL], the gradients in $Z_{\mathrm{DR}}$ (Fig. $7 \mathrm{~b}$ ) and $K_{\mathrm{DP}}$ (Fig. 7c) can be used to locate the regions of heavy rain and small hail along the western and eastern flanks, respectively. The vertical cross section of $\rho_{\text {hv }}$ (Fig. 7d) is a bit noisier in the low levels along the western flank than what was observed along the 0.5-degree slice (Fig. 6d), indicative of some non-uniformity to the drop-size distribution near and below the melting level. 


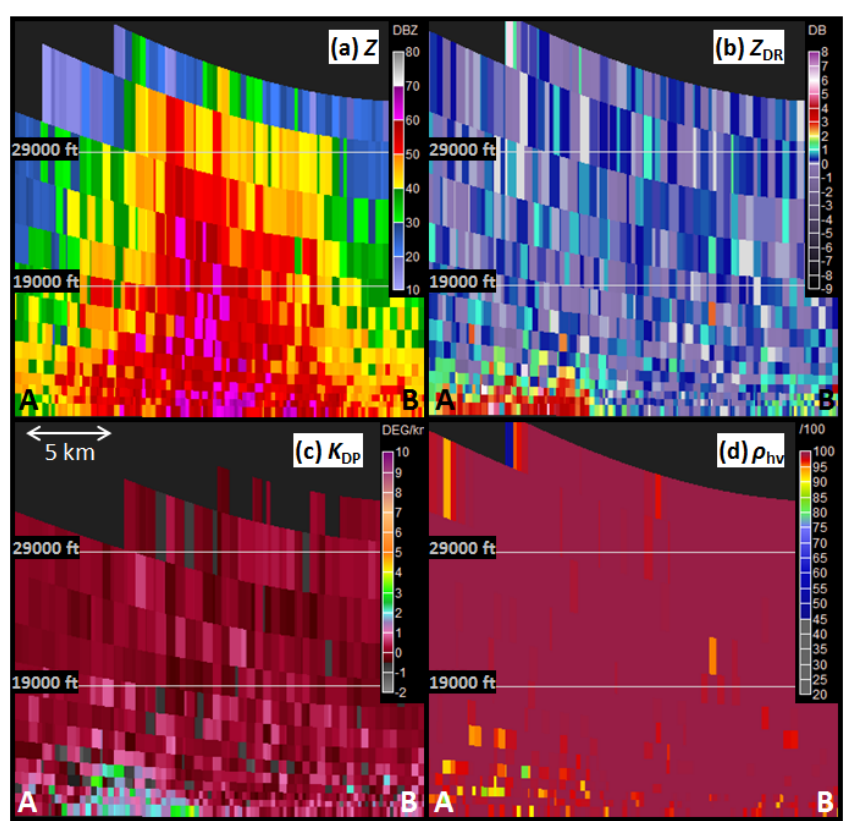

Figure 7. KRGX WSR-88D cross section valid at 2034 UTC 10 June 2013. (a) Reflectivity (dBZ); (b) differential reflectivity (dB); (c) specific differential phase (deg km${ }^{-1}$ ); and (d) correlation coefficient. The location of the cross section is denoted by the white line A-B in Fig. 6d. Elevation values are given in $\mathrm{ft}$ ASL, with the bottom of the cross section located at approximately $2743 \mathrm{~m}(9000$ ft) ASL, which is near the bottom of the 0.5-degree slice over Spanish Springs, NV.

The new instantaneous precipitation rate (IPR) product provided forecasters additional guidance on the location of heavy rainfall during the event. The IPR depicted a region of 51-76 $\mathrm{mm} \mathrm{hr}^{-1}\left(2-3 \mathrm{in} \mathrm{hr}^{-1}\right)$ rainfall rates at 2034 UTC near the Spanish Springs Airport (denoted by the white ellipse in Fig. 6f). It is difficult to formally validate the IPR due to the dearth of precipitation observations in Spanish Springs. A volunteer observer located $1.2 \mathrm{~km}$ east of the Spanish Springs Airport recorded $31.5 \mathrm{~mm}$ (1.24 in) of rain in $10 \mathrm{~min}$ [a rainfall rate of $189.0 \mathrm{~mm} \mathrm{hr}^{-1}\left(7.44 \mathrm{in} \mathrm{hr}^{-1}\right)$ ] from 2037 to 2057 UTC, suggesting the IPR underestimated precipitation rates in the area. Along the eastern flank of the storms, less rainfall and more hail were observed. A NWS cooperative observer located $4.2 \mathrm{~km}$ south-southeast of the Spanish Springs Airport reported storm-total precipitation of $14.5 \mathrm{~mm}$ (0.57 in). Accumulations of pea-sized hail of up to $63.5 \mathrm{~mm}$ (2.5 in) occurred on the eastern side of Spanish Springs (approximately $6.5 \mathrm{~km}$ southeast of the Spanish Springs Airport). The IPR appears a lot noisier in the hail region with values ranging from $<25 \mathrm{~mm} \mathrm{hr}^{-1}$ (1 in $\mathrm{hr}^{-1}$ ) to $>102 \mathrm{~mm} \mathrm{hr}^{-1}\left(4 \mathrm{in} \mathrm{hr}^{-1}\right)$ (Fig. 6f).

\section{b. Pyramid Lake region flash flooding}

A cluster of thunderstorms moved slowly from east to west across the Pyramid Lake, Nevada, region between 2030 and 2300 UTC. Heavy rain over the Lake Range to the east of Pyramid Lake resulted in flash flooding that washed out sections of rural state highway 447 to the west of Winnemucca Lake (see Fig. 2 for locations). A six-panel of 0.5-degree and derived KRGX WSR-88D radar data centered over the Lake Range at 2153 UTC is shown in Fig. 8. Similar to the Spanish Springs case (Fig. 6a), NWS forecasters working the event found it difficult to discriminate between areas of heavy rain and small hail using reflectivity (Fig. 8a) and other legacy radar base data fields (not shown). A joint analysis of $Z_{\mathrm{DR}}$ (Fig. 8b), $K_{\text {DP }}$ (Fig. 8c), and $\rho_{\text {hv }}$ (Fig. 8d) assisted forecasters in analyzing heavy rain as the primary threat over the Lake Range (denoted by the white ellipses in Fig. 8). Closer to highway 447 (denoted by the black boxes in Fig. 8), the $K_{\mathrm{DP}}$ and $\rho_{\mathrm{hv}}$ were lower, on average, suggesting a mixture of rain and hail. Evidence of nonuniform beam filling between Tohakum Peak and highway 447 in the $\rho_{\text {hv }}$ field (Fig. 8d), and output from the HCA (Fig. 8e), provided forecasters additional confidence that hail was present in this region.

The IPR product valid at 2153 UTC provided forecasters additional confidence in the threat for flash flooding (Fig. 8f) to the east of Pyramid Lake. The distribution of IPR values within the region of suspected heavy rainfall is a lot noisier than for the Spanish Springs case (Fig. 6f), with values ranging from 51-152 $\mathrm{mm} \mathrm{hr}^{-1}\left(2.0-6.0 \mathrm{in} \mathrm{hr}^{-1}\right)$. Validating the observed rainfall in this region is difficult as it is sparsely populated and lacks surface mesonet stations that report precipitation. A prolonged period of precipitation was observed in the Pyramid Lake region as shown by the 0.5-degree KRGX loop in Fig. 9. The legacy [dual-polarization] radar rainfall algorithm estimated $25-83 \mathrm{~mm}(1.00-3.25 \mathrm{in})$ [32-95 mm (1.253.75 in)] of precipitation through 2300 UTC along the Lake Range to the east of Pyramid Lake (not shown). The flash flooding along highway 447 was exacerbated by additional rainfall between 2300 UTC 10 June 2013 and 0200 UTC 11 June 2013 as the upper low moved across central Nevada - causing the band of heavier showers within the deformation zone to lift back across the Pyramid Lake region (not shown). 


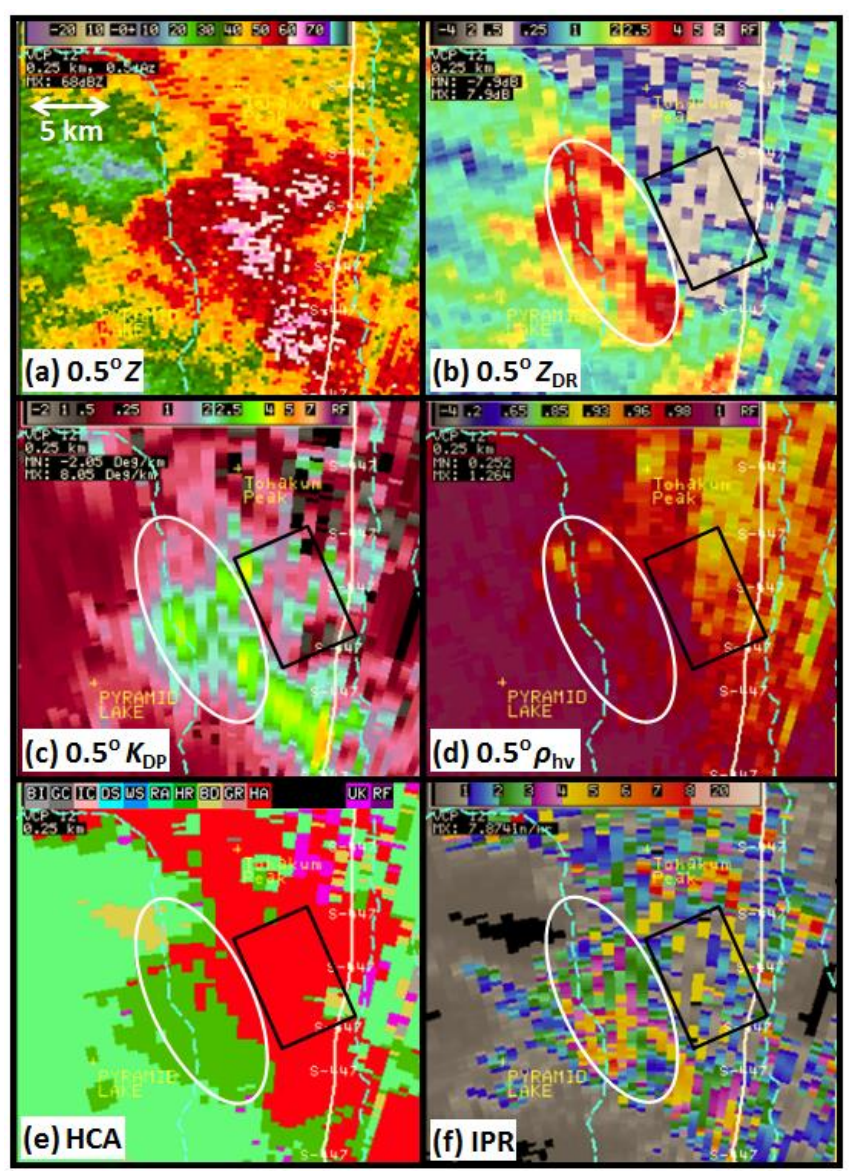

Figure 8. As in Fig. 6, except valid at 2153 UTC 10 June 2013 near Pyramid Lake, NV. State highway 447 is denoted by the white line. Lake and dry-lake boundaries are denoted by the dashed light blue lines. The white ellipses (black boxes) in (b)-(f) denote the locations of thunderstorm activity near the Lake Range (state highway 447).

\section{c. Winnemucca haboob}

Strong outflow boundaries developed to the east of the cluster of thunderstorms that rapidly moved across north-central Nevada. NWS forecasters tracking the outflows on radar found the new dual-polarization base products to be quite valuable in (i) locating areas of lofted dust and (ii) tracking the leading edge of the dust storm. The most prominent outflow was first visible in 0.5-degree KRGX radar reflectivity (Fig. 9a) around 2015 UTC between Hazen and Fallon. A peak gust of $16.5 \mathrm{~m} \mathrm{~s}^{-1}(32 \mathrm{kt})$ was reported 17 min later as this boundary passed the Fallon Naval Air Station (KNFL); however, no visibility reductions were observed. As the outflow passed KNFL, lofted dust from the Alkali Flat (see Fig. 2 for location) was apparent in the 0.5-degree $Z_{\mathrm{DR}}$ (Fig. 9b) and $\rho_{\mathrm{hv}}$ (Fig. 9d) fields immediately upstream of the boundary. The interaction of the outflow boundary with this lofted dust became

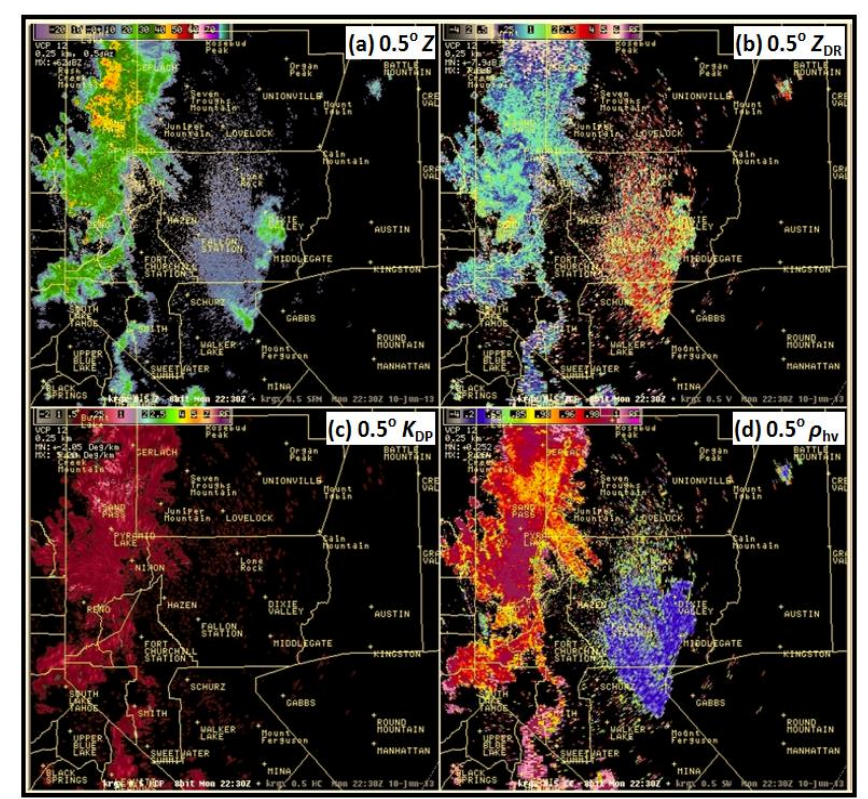

Figure 9. KRGX WSR-88D image valid at 2230 UTC 10 June 2013. (a) 0.5-degree reflectivity (dBZ); (b) 0.5-degree differential reflectivity $(\mathrm{dB})$; (c) 0.5-degree specific differential phase (deg $\mathrm{km}^{-1}$ ); and (d) 0.5-degree correlation coefficient. County boundaries are denoted by yellow lines. Click image for an external animation valid from 1953 UTC through 2318 UTC 10 June 2013.

apparent in the reflectivity (Fig. 9a), $Z_{\mathrm{DR}}$ (Fig. 9b), $\rho_{\mathrm{hv}}$ (Fig. 9d), and visible satellite imagery (not shown) beginning around 2139 UTC. During a postmortem of the event, an image from the Moderate Resolution Imaging Spectroradiometer (MODIS) on the Aqua satellite revealed the appearance of the arc of dust associated with this boundary as it moved across the Stillwater Range east of the Carson Sink (Fig. 10). One can hypothesize that the outflow boundary obtained characteristics of a haboob as it crossed the Carson Sink and interacted with the lofted dust west of Middlegate (see Fig. 2 for location); however, no surface observations are available to confirm visibility in the area.

NWS forecasters had a more difficult time tracking the evolution of the outflow boundaries to the north of Fallon owing to heavier precipitation located down radial (Fig. 9a) and anvil clouds from the parent convection to the west (not shown). The vertical depth of the dust lofted by the outflow may also have been too shallow to be detected by the 0.5-degree slice, located $2737 \mathrm{~m}$ AGL near KLOL. Surface observations from KLOL indicate the outflow boundary transitioned into a haboob as it crossed the Humboldt Sink. As the haboob passed KLOL, the surface visibility was reduced to $0.4 \mathrm{~km}$ for a period of $11 \mathrm{~min}$ 


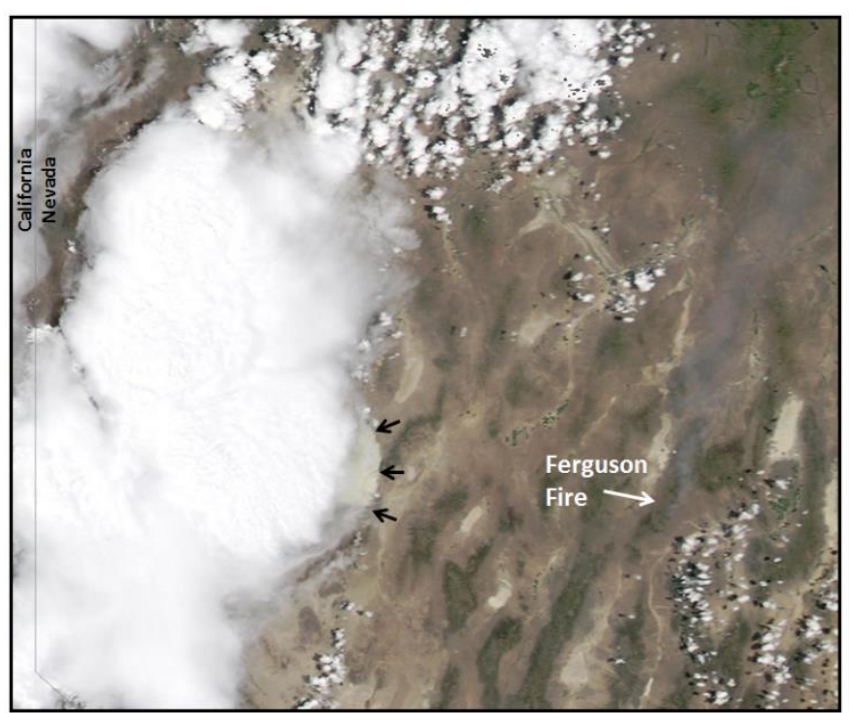

Figure 10. Aqua MODIS image over northwestern $\mathrm{NV}$ at approximately 2115 UTC 10 June 2013. Black arrows denote the location of the haboob. Image courtesy of the Space Science and Engineering Center at the University of Wisconsin-Madison [ge.ssec.wisc.edu/modis-today/index.php].

with a peak wind gust of $24.7 \mathrm{~m} \mathrm{~s}^{-1}$ (48 kt) reported at 2125 UTC.

The haboob remained below the KRGX 0.5degree slice (Fig. 9) as it moved to the east between Lovelock and Winnemucca. As the haboob passed Winnemucca, the surface visibility briefly fell to $4 \mathrm{~km}$ with a peak wind gust of $23.2 \mathrm{~m} \mathrm{~s}^{-1}$ (45 kt) reported at 2348 UTC. The haboob first appeared on the 0.5degree data from the Elko WSR-88D (KLRX) approximately 16 min later at 0006 UTC 11 June 2013 (Fig. 11). A close inspection of the loop presented in Fig. 11 shows two distinct dust boundaries (one moving eastsoutheastward and one moving east-northeastward) that appear to collide and merge near Winnemucca. There is some evidence in visible satellite imagery of these boundaries (not shown); however, high clouds mask their appearance. Recent plowing of dry agricultural fields near Winnemucca also may have contributed to the amount of available dust. Given the limitations of the radar and satellite data, one can only hypothesize that these factors may have enhanced the magnitude of the dust storm near Winnemucca. It should be noted that smoke from the Ferguson wildfire (see Fig. 10 for location) was visible moving south to north across north-central Nevada in the 0.5-degree KLRX $Z_{\mathrm{DR}}$ (Fig. 11b) and $\rho_{\mathrm{hv}}$ loops (Fig. 11d).

Visibility reductions from the haboob led to a $27-$ vehicle accident on Interstate 80 near Winnemucca that resulted in one fatality. Based on sampling from

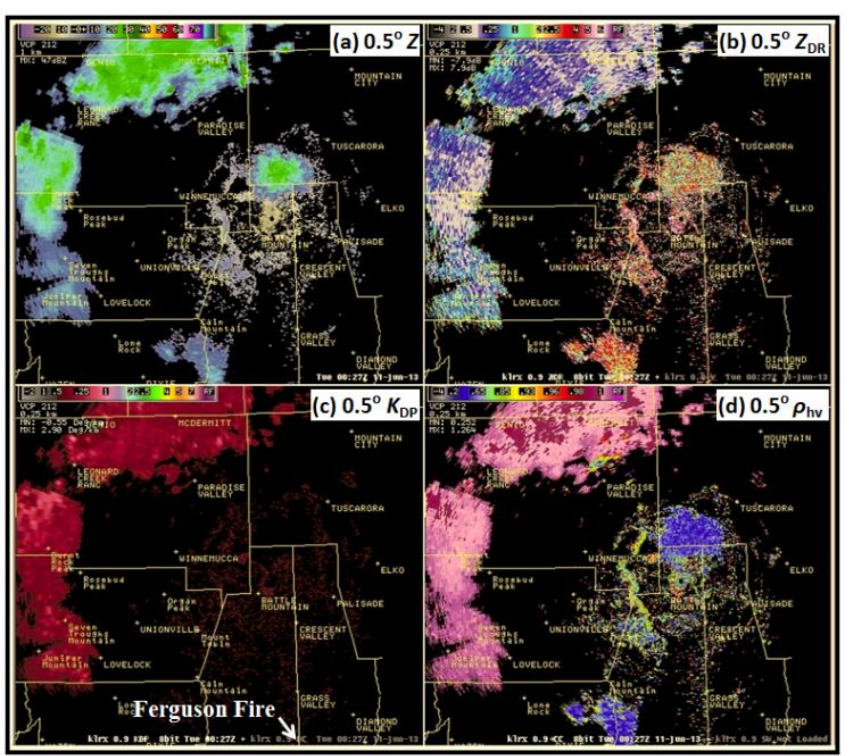

Figure 11. As in Fig. 9, except for the KLRX WSR-88D image valid at 0027 UTC 11 June 2013. The location of the Ferguson Fire is denoted in (c). Click image for an external animation valid from 2338 UTC 10 June 2013 through 0057 UTC 11 June 2013.

the 0.5-degree reflectivity when dust first appeared on the KLRX 0.5-degree scan, the vertical depth of the haboob near Winnemucca was approximately $1500 \mathrm{~m}$ AGL. Farther to the south, sampling from the KRGX radar indicates the haboob reached heights of approximately $4000 \mathrm{~m}$ AGL. An aerial photo taken by an airline pilot when the haboob was located approximately $50 \mathrm{~km}$ to the south of Winnemucca supports this analysis (Fig. 1c).

\section{Concluding comments}

The deployment of dual-polarization radar technology to the NWS WSR-88D radar network has provided forecasters with a number of new products to analyze severe weather phenomenon and discriminate hydrometeor type and size. Many of the mesoscale features described in this paper would have gone largely undetected using only legacy radar reflectivity and velocity products. As was shown in the examples from Spanish Springs and Pyramid Lake, Nevada, the joint analysis of legacy and dual-polarization variables can assist operational forecasters in delineating regions of heavy rain from small hail in low-centroid storms. These cases also demonstrated how the new IPR product can aid forecasters in locating storms that are producing locally heavy rainfall. The Winnemucca, Nevada, case highlighted how forecasters can use dual-polarization variables to track outflow boundaries and non-meteorological targets such as blowing dust. 
Significant challenges remain in the analysis of severe convection and heavy precipitation across large portions of the western United States due to low-level coverage gaps from high-elevation radars. These gaps can make tracking shallow surface outflow boundaries nearly impossible and also can impact the quality of dual-polarization products and precipitation estimates, particularly at longer distances from the radar. The cases shown from Spanish Springs and Pyramid Lake (located within a 40-km radius of the KRGX radar) demonstrated the utility of the dual-polarization base and IPR products because the convection was deep enough to be captured by the lowest elevation slice. Across most of northwestern Nevada, the 0.5-degree beam from KRGX overshoots most populated valleys by at least $1219 \mathrm{~m}(4000 \mathrm{ft})$. This overshooting can result in the radar not detecting low-level outflow boundaries, thereby underestimating storm-total precipitation, especially when interrogating low-centroid storms.

Acknowledgments. The authors thank Gary Barbato, Tony Fuentes, Jessica Kielhorn, and Scott McGuire from NWS Reno for their assistance in gathering data for this study. A special thanks to Brian Brong, Tony Fuentes, Jon Mittelstadt, Chris Smallcomb, and Jim Wallmann from NWS Reno, as well as Donald Dumont (NWS Elko) and Michael Staudenmaier (NWS Western Region Headquarters) for their preliminary reviews. Comments from two anonymous reviewers greatly enhanced this manuscript. The views expressed are those of the authors and do not necessarily represent those of the National Weather Service.

\section{REFERENCES}

Brong, B. S., 2005: A study of the flash flood potential in western Nevada and eastern California to enhance flash flood forecasting and awareness. M. S. thesis, Atmospheric Science Program, University of Nevada-Reno. $77 \mathrm{pp}$.

Bunkers, M. J., cited 2013: Precipitable water plots. National Weather Service, Rapid City, SD. [Available online at www.crh.noaa.gov/unr/?n=pw.]

Changery, M. J., 1983: A dust climatology of the western United States. U.S. Nuclear Regulatory Commission Rep. NUREG/CR-3211, 25 pp. [Available from National Climatic Data Center, 151 Patton Ave., Room 120, Asheville, NC 28801-5001.].

Idso, S. B., R. S. Ingram, and J. M. Pritchard, 1972: An American haboob. Bull. Amer. Meteor. Soc., 53, 930935.
Istok, M. J., and Coauthors, 2009: WSR-88D dual polarization initial operational capabilities. Preprints, 25th Conf. on Interactive Information Processing Systems, Phoenix, AZ, Amer. Meteor. Soc., 15.5. [Available online at ams.confex.com/ams/pdfpapers/ 148927.pdf.]

Kaplan, M. L., R. K. Vellore, J. M. Lewis, and M. Young, 2011: The role of unbalanced mesoscale circulations in dust storms. J. Geophys. Res., 116, D23101, doi:10.1029/2011JD016218.

Kumjian, M. R., 2013a: Principles and applications of dualpolarization weather radar. Part I: Description of the polarimetric radar variables. J. Operational Meteor., 1 (19), 226-242.

2013b: Principles and applications of dualpolarization weather radar. Part II: Warm- and coldseason applications. J. Operational Meteor., 1 (20), 243-264.

, 2013c: Principles and applications of dualpolarization weather radar. Part III: Artifacts. $J$. Operational Meteor., 1 (21), 265-274.

Lewis, J. M., M. L. Kaplan, R. Vellore, R. M. Rabin, J. Hallett, and S. A. Cohn, 2011: Dust storm over the Black Rock Desert: Larger-scale dynamic signatures. $J$. Geophys. Res., 116, D06113, doi:10.1029/2010JD 014784.

Orgill, M. M., and G. A. Sehmel, 1967: Frequency and diurnal variation of dust storms in the contiguous U.S.A. Atmos. Environ., 10, 813-825.

Saxion, D. S., and R. L. Ice, 2012: New science for the WSR-88D: Status of the dual polarization upgrade. Preprints, 28th Conf. on Interactive Information Processing Systems, New Orleans, LA, Amer. Meteor. Soc., 5. [Available online at ams.confex.com/ams/ 92Annual/webprogram/Manuscript/Paper197645/NEX RAD_DP_Status_28th_IIPS_Jan2012.pdf.]

Steenburgh, W. J., J. D. Massey, and T. H. Painter, 2012: Episodic dust events of Utah's Wasatch Front and adjoining region. J. Appl. Meteor. Climatol., 51, 16541669. 